\title{
Editorial
}

The academic predicament of the twenty-first century seems to be the everincreasing fragmentation of knowledge, much lamented, but incessantly produced and reproduced in quests for authority and expertise. Disciplinary and intra-disciplinary confines locate power to politics, authority to law, society to sociology, and distinguish the social sciences from non-scientific forms of expression, that is the anecdotes, tales and fictions of humanities. Though social sciences and humanities, both, have the human at the core, often the social sciences claim to represent a scientific approach, defined as systematic, generalizable, reproducible studies of human populations. The precise boundaries for the allocation of knowledge depend on historical influences that have shaped academic practices, the languages that led to (often one-directional) flows of knowledge, also accumulations of physical, intellectual and cultural encounters between various academic cultures and subcultures. How can these fragmentations be transcended? This requires not only an intention to work in a multi-, inter- or trans-disciplinary fashion, across language barriers or across cultures, but also a transformation of contemporary practices that reward forms of bounded knowledge.

Political Anthropological Research on International Social Sciences (PARISS) seeks to encourage transversal social inquires so as to support flows rather than academic enclosures and to cut across conventional planes of scholarship. Here, as has previously been noted, "[ $t]$ he notion of transversal lines is intended to articulate the distinctive contributions of various forms of knowledge, depending on the specific phenomena, trajectories and problems that are in question."1 By doing so, PARISS seeks to reinvigorate scholarly engagements untroubled by canonic approaches and to provide a space for outstanding scholarship, marginalized elsewhere due to academic conventions. Drawing transversal lines requires not only a different way of thinking, but different

1 Tugba Basaran, Didier Bigo, Emmanuel-Pierre Guittet, and R.B.J. Walker, eds., International Political Sociology: Transversal Lines (Oxon \& New York: Routledge, 2017), 1. 
intellectual practices - it requires intellectual collaborations between fragmented fields of knowledge. This includes collaborations between and among disciplines, but also linguistic collaborations that go beyond the anglophone canon, allowing the creation of novel, innovative and critical intellectual spaces. As such, we would like PARISS to become a comitium, an open meeting space for scholars of various backgrounds seeking to draw transversal lines.

In an effort to transcend fragmentations by transforming practices, our first issue starts with a collective article on "The Art of Writing Social Sciences: Disrupting the Current Politics of Style". As a critique of the practices that condition the production of hierarchies and unequal distributions of status in our profession, we've also chosen to use virtual dice to randomly determine the order in which the names of authors involved in writing this PARISS collective paper appear. By following a logic of randomness, wherein the chances of being first, second, or last are equal for all and reset with each throw of the dice, we make a break with both the arbitrary yet stable logic of an alphabetical ordering that privileges those whose names fall at the beginning of the alphabet, as well as the politics of rank, age and gender (amongst other criteria) which so often structure the claims around who takes the most credit for a paper. In terms of the article's substance, through a critical engagement with substantive and stylistic guidelines dictated by dominant journals in the social sciences, this article enquiries what it means to write like a social scientist in the twenty-first century. In interrogating the historical-contextual origins of conventions that so strongly shape the world of academic publishing and, dare we say, reasoning, we raise questions about the conditions of the present and the naturalization of standards on how to write a scientific article. As a consequence of this exploration, we propose alternative guidelines that a new journal such as ours has to present to its anticipated authors and readers. One of the many practices that we seek to cultivate, in hope of a subtle, but longterm effect on academic writing is the provision of running themes that last over three years and allow for an evolving form of interaction and conversation between academic scholars of various disciplines, languages and cultural backgrounds.

\section{Politics of Style}

This first running theme initiated by the collective article on politics of style wants to engage with substantive and stylistic guidelines dictated by dominant Anglophone journals in the social sciences and the discriminatory practices they imply. What is at stake is not so much a matter of language as such, as a 
certain academic style that becomes imbued with presumptions about the meaning of science, elegance, efficiency, and tradition, as defined by dominant positions. How can the pretence that a language presenting itself as a universal language of reason and aesthetics, which is in fact situated, local, and particularistic, be challenged? What sort of alternative practices can be found in reflexive, postcolonial, and feminist traditions of writing? We hope to have initiated a conversation, a "disputatio" which will continue in the upcoming six issues 2020-2023, be they in the form of collective responses or individual contributions.

The articles of Mariella Pandolfi and Lynda Dematteo, entitled "Anthropology from Dissonance to Ambiguity: Breaking the Deadlock," and of Anna Leander, "Composing Collaborationist Collages about Commercial Security," present powerful and elegant ways of writing social sciences, without adhering to the doxa of a politics of style which creates this sense of boredom and repetition that so many of us have when we open and bleakly peruse through a social sciences journal. They are examples of creative thinking and writing.

\section{Problematizing Transversal Lines and their Methods}

The second running theme of this issue is related to the core of the PARISS journal: transversality. How can transversal lines be created between disciplines? How can we travel between and across disciplines, not as a tourist or passer-by but as a multi-sited anthropologist, an international nexialist, an historian of the dynamics of fields of power which first structure the relational positions of actors, and second, account for their trajectories which create encounters, collisions, fragmentations or collusions regarding emergent interests, disinterests, indifference or ignorance on some topics and not others. What has been called transnational or internationalisation by an international relations colonized by political science has to be (re)explored and deepened in order to construct bridges and translations. It calls for a discussion about problematisations, beyond methods, that are powerful enough to create different paths for understanding and writing through transversal lines in a coherent way.

Giving our readership a taste of what has been termed a "globe-trotting sociology," an approach which strongly resonates with the PARISS project, we have two pieces that engage with the work of French sociologist Yves Dezalay. Translated from French to English, the first takes the form of an interview with Yves Dezalay himself, "Interview with Yves Dezalay: Investigating the Internationalisation of State Nobilities," carried out by Antonin Cohen and Didier Bigo for the journal Cultures \& Conflits. The second is an introductory article 
authored by Antoine Vauchez that situates the central role of Yves Dezalay in reinvigorating a Bourdieusian approach to the social sciences in France as well as globally for the sociology of law and lawyers. For issues to come, we invite articles that discuss different ways of addressing the topic of transnational elites, the formation of a new class of global elites, transnational guilds, internationalisation of state nobilities, and so forth by presenting their informed research on specific groups, be they in these dominant positions or, on the contrary, considered as disenfranchised groups, the so-called left behind, and or the understudied average groups, the normalised, the "quidams" of the everyday.

Practices of Mobility and Lived Experiences

A third running theme engages with the lived experiences of people, placing ontological primacy on liveable lives and situating social worlds as contexts. Be they people on the move, those acting in solidarity with, or against, these travellers or mobile people, or individuals embedded in other sets of relations which cause them to feel (in)secure, this running theme engages ethnographically with such practices, processes and people. Beginning with the ethnographic, theoretical claims are thus empirically based, challenging prefabricated categories of thought and accounts of power.

The articles by Nicholas De Genova and Martina Tazzioli respectively entitled "The Convulsive European Space of Mobilities" and "What is Left of Migrants' Spaces? Transversal Alliances and the Temporality of Solidarity" precisely disrupt dominant statist and presentist ways of thinking about human mobility, reactions against it, and the alliances which emerge to support this movement, recasting discursive frameworks in light of the complexities of lives lived. Similarly, the paper by Xymena Kurowska, entitled "The Secondary Gains of Neoliberal Pain:The Limits of Consolation as a Response to Academic Anguish" adopts a narrative, autoethnographic tale of academic torment which problematizes a 'doer, done' imaginary, speaking also to our running theme on Misère du monde académique, which we introduce below.

We will start the next issue with a follow-up of these themes and will bring in four more new running themes.

For the running theme on the politics of knowledge and higher education, we seek to publish reflections on the sociology of higher education, the politics of 
intellectual life and the politics of collective freedom. In recent years, many works have focused on the political economy of higher education and the transformation of pedagogy and research under conditions of neoliberalism, such as the rise of professional administrators and managerialism and the significance of capital in institutional decision-making and the consequences hereof. Starting from these studies, we ask ourselves how it is possible that such a recent system now appears as a necessity for organizing higher education? How is it possible that academic freedom, which works as the condition of pedagogy, has been transformed into the will to serve, to become the best in an arbitrary ranking process, where the academic becomes an employee, a salesperson of an institution of higher learning, employed to sell diplomas? We welcome critical engagement with contemporary politics of higher education that fragment the circulation of knowledge and/or to the contrary promote new ways of circulation. Manuscripts could engage, for example, with practices of academic life and its reproduction, technological transformations and their impact, capitals and class struggles in the academic space, and so forth. The analyses can be institution-specific or transnational, and deploy (auto)ethnographic, sociological, historical, post- and decolonial forms of engagement.

Taking inspiration from the book of Pierre Bourdieu Homo Academicus and of the collective work Misère du monde (or The Weight of the World in English), ${ }^{2}$ we are proposing a running theme on social suffering in the academic world. In addition to mapping the structural transformations that have remodeled the university as a space of education, knowledge production, and intellectual curiosity, we envision this running theme as a chronicle or living archive of everyday experiences of domination, abjection, exclusion, and exploitation in the ivory tower. From picket line slogans heralded by faculty and students on strike ("Education not Marketisation"; "Larger classes, less attention"; "Keats not cuts"; "Our working conditions are your learning conditions") to negative affirmations that are increasingly employed to describe everyday life in academia (Academia is an exploitative system dependent on the labor of an underpaid, precarious underclass; Academia is an "anxiety machine"), diffuse forms of denunciation and cries of frustration merit attention (and alternative proposals for reasserting pedagogy as the first role of higher education).

2 Pierre Bourdieu et al., The Weight of the World: Social Suffering in Contemporary Society, trans. Priscilla Parkhurst Ferguson et al. (Cambridge: Polity Press, 1999). 
In many ways, the CovID-19 pandemic has brought to the fore with great acuity the destructive toll of neoliberalism and the diffusion of a financialized managerial logic on sectors such as health, education, and agriculturethough not only. From the severe strain put on medical and public health professionals working with limited means, to the realization of many parents now at home with their children that teachers merit greater recognition, to the precarious many whose insecure working conditions privy them from the privilege of being able to work from home, this global pandemic has revived debates about a globalized capitalistic system which prioritizes "cost reductions," "austerity for public services," "benefits of online surveillance" and "productivity" over justice, equality, and freedom. We thus see these contradictions between capital and care, between neoliberal managerialism and professional autonomy as reflective of the same struggles taking place in academia, and welcome articles on these topics.

For both themes and their interwoven logics, we would like to see individual papers about the conditions of social suffering of the self, but also of colleagues, of institutional transformations seen from below, some would say from the heart, and from lived experiences. We want to also encourage our formula of collective articles, written perhaps under pseudonyms, as a way of giving a voice to those who cannot claim alone their forms of suffering because they are often the most fragile in terms of structural positions.

Styles of Governing and Forms of Governmentality

On the running theme of styles of governing and forms of governmentality, we welcome contributions that characterize and address distinctive modes of exerting power and control over human populations, be they geographically dispersed or locally concentrated, as well as non-human life forms and material objects. We are notably interested in papers that make transversal connections across political, social, and economic contexts, pushing beyond binary categories that typically order our understanding of the world (i.e. authoritarian/ democratic regimes; traditional/modern societies; core/periphery economies). The notions of state of exception, of state of emergency, of derogations to the rule, of efficiency of the executive as a priority over liberties, have been used and overused, too often as if they were altogether synonymous. We certainly need to deepen the understanding of the practices encapsulated under these different terminologies. A majority using its power to change the rules and oppress minorities (be they political, religious, ethnic or of different nationalities) may not use a state of exception as a form of governing, but they may 
create authoritarianism. A permanent state of emergency as a way of life in societies governed by speed, acceleration, and online data, may transform politics and democratic practices without any state of exception or formal emergency rules. The apology of order, obedience, and transparency of the citizen towards their authorities may challenge democracy and equality, even when these calls for order in the name to protect "populations" seemed legitimate. At a time when travel bans have been used to contain migrants and microbes alike, when quantitative reasoning enacts distant and near futures to govern uncertainty in the present, and when global disparities in experiences of violence and inequality have perhaps never been so far and wide, the contemporary moment seems as good a time as any to revisit questions of power and politics entwined in the governance of people and things. Articles on the dynamics of these long transformations, the everyday practices of resistance or of "slowing the machinery" are most welcome but should not be reduced to cases of "liberal democracies". Moreover, whilst critical approaches to government, governance, and governmentality tend to heed greater analytical weight to the powerful, we invite contributions that adopt a dialectical approach to power and resistance. Thus, we look forward to contributions that engage critique in such a way that not only gives texture to the present order of things, but that also makes space for political, social, and ethical reinvention.

On the running theme of politics of translation, we welcome contributions that engage with the significance of language, translation and by implication culture for analyzing contemporary politics of knowledge and academic boundaries. Whilst there is a wealth of research on these topics, this knowledge is highly fragmented due to linguistic boundaries. Monolingual research and publication remain largely the norm. What would be effective practices of piercing through linguistic boundaries? How can we promote and ameliorate access to knowledge across linguistic boundaries? Translations can provide new spaces for thought, reflection and political action. By speaking of translation, we are not limiting our analysis to linguistics, semantics, semiology and their relations to politics, we insist on the fact that translation appears as a dynamic at work any time a process of negotiation and transformation operates from one plan or scape to another one, be it about subject-matters, mediums, thoughts, styles, meanings, as soon as this dynamic is effectively (re)framing our patrimony of dispositions and the enactment of our practices. Political anthropology can itself be considered as a study of the politics of translation. 
We hope that, in our first issue of the first volume of PARISS, we have been able to offer our readers a guide to these research initiatives and running themes. In the many volumes and issues of PARISS still to come, we welcome with open arms papers which engage with these themes, or propose original articles in different directions that open up new spaces for transversal thought.

The Editors of PARISS

\section{Bibliography}

Basaran, Tugba, Didier Bigo, Emmanuel-Pierre Guittet, and R.B.J. Walker, eds. International Political Sociology: Transversal Lines. Oxon \& New York: Routledge, 2017.

Bourdieu, Pierre, Alain Accardo, Gabrielle Balazs, Stéphane Beaud, François Bonvin, Emmanuel Bourdieu, Philippe Bourgois, et al. The Weight of the World: Social Suffering in Contemporary Society. Translated by Priscilla Parkhurst Ferguson, Susan Emanuel, Joe Johnson and Shoggy Waryn. Cambridge: Polity Press, 1999. 